\title{
Infections in British clinical laboratories 1980-81
}

\author{
NR GRIST \\ From the University of Glasgow, Department of Infectious Diseases, Ruchill Hospital, Glasgow, G20 9NB
}

SUMmARY This survey through the Association of Clinical Pathologists was continued and extended for 1980-81, with the help of the Institute of Medical Laboratory Sciences. Hepatitis maintained a low attack rate of 26/100 000 person-years, including only three cases of hepatitis B probably attributable to laboratory work (attack rate 9). Nineteen cases of tuberculosis (attack rate 56) included 14 of probable occupational origin (attack rate 41 ) half of which involved post-mortem or mortuary work. Thirteen bacterial infections of the bowel (attack rate 38, predominantly shigellosis) involved almost exclusively microbiology MLSOs, with 10 attributed to laboratory work (attack rate 29). The seven other infections included 4 of occupational sepsis in morbid anatomy and post-mortem workers. There appears to be scope for improvement in bacteriological bench techniques particularly at the faeces bench and for reduction in the hazards of tuberculosis and sepsis for morbid anatomy and mortuary workers.

During the decade of the seventies, the "ACP Survey" of hepatitis in the staff of clinical laboratories in Britain showed a marked fall in incidence after $1974^{12}$. For 1979 the questionnaire to members of the Association of Clinical Pathologists (ACP) was modified on a trial basis to record not only hepatitis but also other types of infection. For the next two years, this successful modification was continued and questionnaires were sent not only to members of the Association but also to the heads of laboratories on a supplementary list compiled with the assistance of the Institute of Medical Laboratory Sciences (IMLS). The results of the survey covering 1980 and 1981 are presented here.

\section{Material and methods}

The confidential questionnaire form for the 1979 survey $^{1}$ was modified to accept data from the two years and sent out with ACP literature early in 1982. The numbers of staff in different grades and disciplines were recorded as at 1 January 1981 and 1 January 1982 , counting part-time staff each as 0.5 , and summated to give a reasonable estimate of the populations at risk in person-years. This allowed attack rates per 100000 person-years of exposure to be calculated for the various infections encountered, as in previous surveys. No attempt was made to distinguish and exclude non-occupational infections since this is often difficult to do even with much more complete information than can reasonably be

Accepted for publication 1 September 1982 sought by an acceptable questionnaire. Supplementary information was obtained by follow-up enquiry in respect of hepatitis cases and other cases where data were incomplete or ambiguous. The same form, with a distinguishing mark, was sent directly by post to the heads of laboratories on the supplementary IMLS list. In order to assess any bias arising from possible differences between this population and that covered by the continuation of the established "ACP Survey", the returns from the two groups were analysed separately for comparison before consolidation.

\section{Results}

Returns were received from 260 "laboratories" in the UK. As usual, these ranged from a few singlediscipline units to large Divisions covering several hospitals. Infections were recorded in $37(14 \cdot 2 \%)$, mostly single but including unrelated pairs of infection in seven, one pair of streptococcal infections, and one group of four associated cases of tuberculosis. Thirty-two returns $(12.3 \%)$ came from the supplementary IMLS list and included three single bowel infections.

\section{SURVEY POPULATION}

The composition of the populations covered by the two phases of the survey is summarised in Table 1 , showing close similarity in the proportions of staff in the four broad occupational groups each year. Detailed breakdown of the January, 1981 population (Table 2) confirmed the close similarity of the 
Table 1 Composition of population surveyed (person-years)

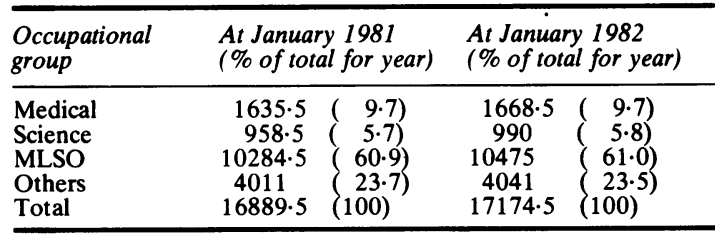

two study populations but with somewhat higher contributions by the IMLS group to "Medical, haematology" (14.7\%), "MLSO, haematology" $(16.6 \%)$ and "Porters, assistants etc" $(20 \cdot 3 \%)$. This reflects the relatively higher contribution of Blood Transfusion Centres to the smaller IMLS groups (an eighth of the study population), since four Centres responded in each group (with no recorded infections): the staff of these Centres is large (totalling 2198 person-years), and blood transfusion is classified under "haematology" in the analysis. It seemed justifiable to combine the total data from both groups for the more detailed analysis since no important bias from this source appeared to be likely.

\section{INCIDENCE OF INFECTIONS}

Table 3 summarises the data in a similar form to that used for previous surveys. Reported infections were confined to the medical, MLSO and "others" groups. As in $1979^{1}$, the predominant infections were tuberculosis and bowel infections, with very similar attack rates to those calculated from the smaller numbers of 1979. As in 1979, a few other infections were recorded, and various kinds of hepatitis.

\section{Hepatitis}

Table 4 summarises the nine infections-two of hepatitis A, five of hepatitis B (including one silent $\stackrel{9}{+}$ infection) and two cases with negative tests for $\bar{c}$ hepatitis B markers of which one had glandular fever. The other was a mild case with negative $\frac{\text { ? }}{\circ}$ Hepatest and hepatitis A IgM test, with insignificant $\stackrel{\mathbb{Q}}{\varrho}$ titres of antibody to herpes simplex and $\%$ cytomegalovirus infections and with IgG but not $\vec{O}$ IgM for Epstein-Barr virus, possibly a "non-A non-B" infection of a haematologist perhaps $\vec{\omega}$ infected by contact with a patient.

One of the five hepatitis B infections was symp- 용 tomless, detected only by routine serological screen- $\omega$ ing after a laboratory accident (type unspecified): i positive results were found by RIA, RPH and $\vec{N}$ hepatitis Be antigen tests. In the absence of illness, $\overrightarrow{ }$ this case would not normally be included in the sur- 음 vey but is reported here because of its association $\overrightarrow{ }$ with a laboratory accident involving a biochemistry $\mathbb{D}$ MLSO, one of the known higher-risk groups. Three others, from which the attack rates were calculated $\underset{\Sigma}{2}$ as for previous surveys, included a phlebotomist working in a hospital for mentally subnormal $\bigodot_{\infty}$ patients and a medical morbid anatomist who suf- $\omega$ fered an unspecified laboratory accident; the source of the infection of the third case was unknown. Another case acquired infection from a chronic carrier spouse.

The two hepatitis A infections were probably ran- $\stackrel{\mathbb{D}}{\perp}$ dom, non-occupational infections. Attack rates for $\overrightarrow{\overrightarrow{7}}$ clinical hepatitis B infections probably attributable 3 to infection during work were calculated and are $\supsetneq$ given at the foot of Table 4 -they are encouragingly? low.

Tuberculosis
The 19 cases summarised in Table 5 include one

Table 2 Comparison of the two component populations (based on January 1981 figures)

\begin{tabular}{|c|c|c|c|}
\hline Occupational group & "ACP group"* & $\begin{array}{l}\text { "IMLS group"* } \\
\text { (\% of total) }\end{array}$ & Combined group (100\%) \\
\hline $\begin{array}{l}\text { Total } \\
\text { Medical } \\
\text { Science } \\
\text { MLSO } \\
\text { Others } \\
\text { Medical, Morbid anatomy } \dagger \\
\text { Science, Morbid anatomy }{ }^{\dagger} \\
\text { MLS̋O, Haematology } \dagger \\
\text { Porters and assistants } \dagger \\
\text { Domestics } \dagger\end{array}$ & $\begin{array}{c}14732 \cdot 5 \\
1463 \\
844 \\
9012 \\
3413 \cdot 5 \\
540 \cdot 5 \\
365 \\
33 \\
462 \cdot 5 \\
2474 \cdot 5 \\
197 \\
513 \\
643\end{array}$ & $\begin{array}{cc}2157 & (12.8) \\
172.5 & (10.5) \\
114.5 & (11.9) \\
1272.5 & (12.4) \\
597.5 & (14.9) \\
47.5 & (8 \cdot 1) \\
63 & (14.7) \\
1 & 2.9) \\
66 & (12.5) \\
492 & (16.6) \\
17 & (7.9) \\
130.5 & (20.3) \\
77 & (10.7)\end{array}$ & $\begin{array}{c}16889 \cdot 5 \\
1635 \cdot 5 \\
958 \cdot 5 \\
10284 \cdot 5 \\
4011 \\
588 \\
428 \\
34 \\
528 \cdot 5 \\
2966 \cdot 5 \\
214 \\
643 \cdot 5 \\
720\end{array}$ \\
\hline \multicolumn{4}{|c|}{ 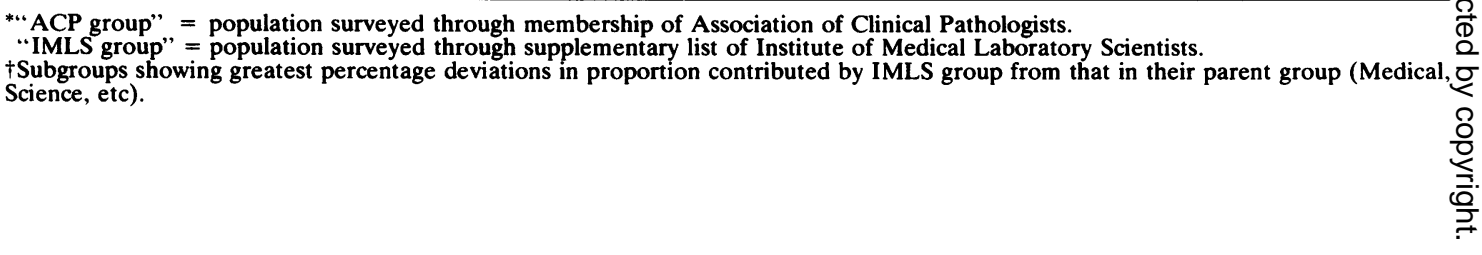 } \\
\hline
\end{tabular}


Table 3 Cases and attack rates of infections in laboratory staff, 1980-81

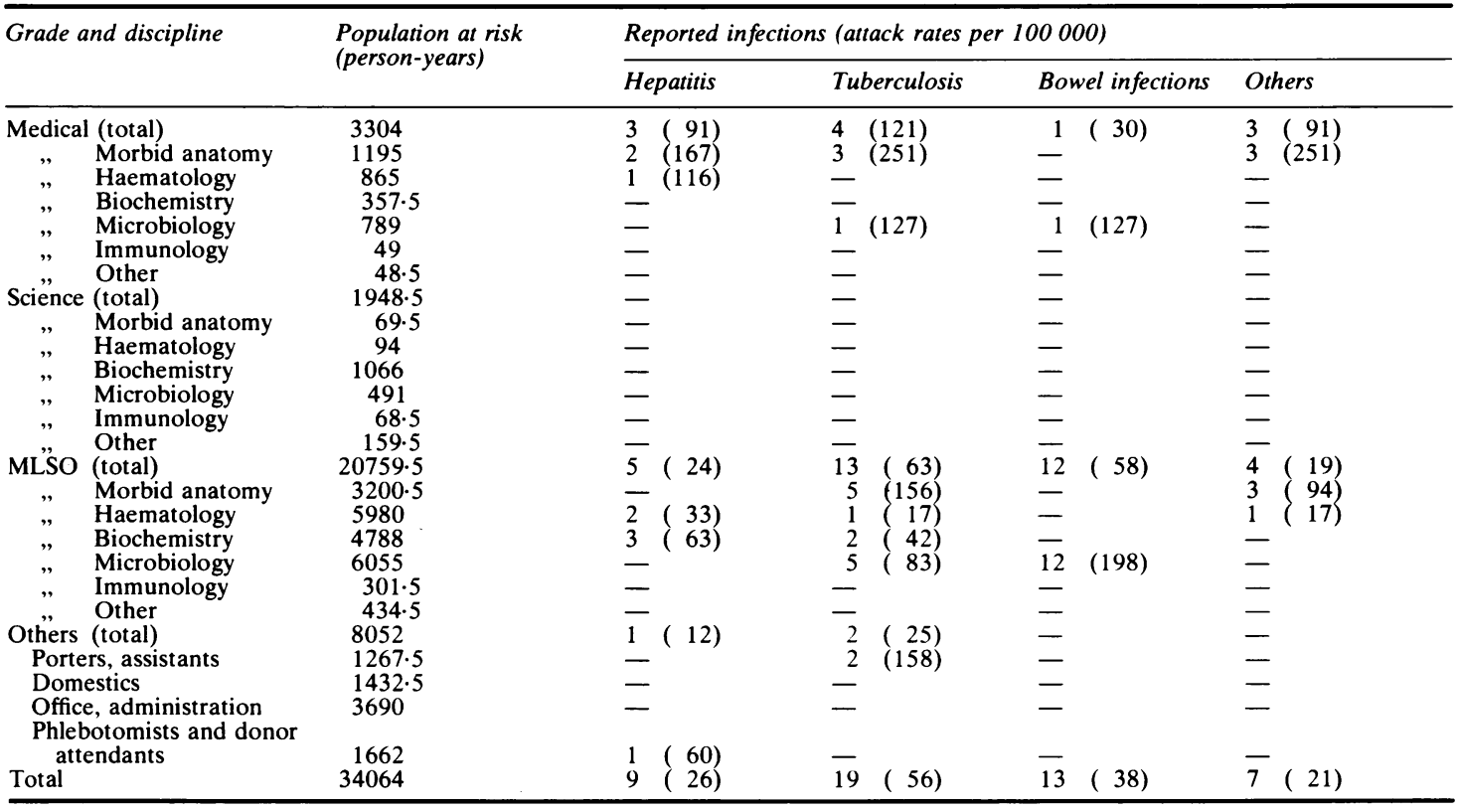

Table 4 Hepatitis cases

\begin{tabular}{llll}
\hline Type & Year & Occupation & Comments \\
\hline A & 1981 & MLSO, Biochemistry & \\
A & 1981 & MLSO, Haematology & Infected by spouse (carrier) \\
B & 1980 & Medical, Morbid anatomy & Laboratory accident \\
B $^{*}$ & 1980 & Medical, Morbid anatomy & Works in hospital for mentally subnormal \\
B $^{*}$ & 1980 & MLSO, Haematology & Silent infection detected by routine \\
B & 1981 & Phlebotomist & Screening; laboratory accident \\
? (not B) & 1981 & MLSO, Biochemistry & Infected by patient contact \\
Epstein-Barr virus & 1981 & Medical, Haematology & MLSO, Biochemistry \\
\hline
\end{tabular}

"Clinical "attributable" hepatitis B attack rate $=16 / 100000$ MLSO Haematology

83/100 000 Medical Morbid anatomy 50/100 000 Phlebotomists

$9 / 100000$ Total staff

"suspected", unconfirmed case in an MLSO (Morbid Anatomy). The mean age was 41 yr (range 22-65 yr; 4 not known) and 16 were men. Not all cases were occupationally derived and several were clearly due to reactivation of pre-established infection. Occupational exposure seemed to be the cause in 14 cases, half of whom were involved in postmortem or mortuary work. The "suspected" case was also a mortuary technician. Case 7 worked in a mycobacteria laboratory but was exposed to tuberculosis in childhood, became Mantoux-positive and was followed up at a chest clinic: reactivation of endogenous infection was suspected. The attack rates for tuberculosis probably attributable to occupation are given at the foot of Table 5. They also reflect the higher incidence in groups involved in mortuary and post-mortem work. The rate for medical morbid anatomists is inflated by a group of cases in one laboratory where case to case infection is a possibility as well as common source exposure of this group and their mortuary attendant.

\section{Bowel infections}

The hepatitis A infections (Table 4) probably belong in this group, but Table 6 lists the bacterial 
Table 5 Tuberculosis cases

\begin{tabular}{|c|c|c|c|}
\hline Case No & Year & Occupation & Comments \\
\hline $1^{*}$ & 1980 & Medical, Morbid anatomy & Detected by routine $x$-ray; exposed in PM room \\
\hline $2 *$ & " & ," & First case of four \\
\hline $\begin{array}{l}3^{*} \\
4\end{array}$ & , & $", \quad$ " $"$, & Contact of case 2 \\
\hline $\begin{array}{l}4 \\
5^{*}\end{array}$ & $"$ & "Microbiology & Old lesion (prostatic: Asian) \\
\hline $\begin{array}{l}5^{*} \\
6^{*}\end{array}$ & $"$ & MLSO, & See text \\
\hline 7 & ", & $"$ & $\overline{9}$ reactivation-see text \\
\hline $8^{*}$ & $"$ & PM̈ technician & ? occupational \\
\hline $9^{*}$ & & Mortuary attendant & Contact of case 2 \\
\hline $\begin{array}{l}10^{*} \\
11\end{array}$ & 1981 & PM technician & ? occupational \\
\hline $\begin{array}{l}11 \\
12\end{array}$ & 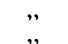 & Mortuary technician & Suspected case \\
\hline $13^{*}$ & $"$ & $\begin{array}{l}\text { MLSO, Haematology } \\
\text { Biochemistry }\end{array}$ & Urinary tract infection \\
\hline $14^{*}$ & $"$ & $"$ & Tuberculous meningitis \\
\hline $15^{*}$ & , & " Microbiology & Centrifugation defect \\
\hline 16 & " & $", \quad$, & Reactivation of old lesion \\
\hline $\begin{array}{l}17^{*} \\
18^{*}\end{array}$ & , & Mortuary attendant & Contact of case 2 \\
\hline $\begin{array}{l}18 \\
19^{*}\end{array}$ & $"$ & Cytology screener & - \\
\hline & & Porter & - \\
\hline
\end{tabular}

${ }^{*}$ Possibly attributable confirmed cases, attack rate $=251 / 100000$ Medical Morbid anatomy $62 / 100000$ MLSO

49/100 000 " Microbiology

42/100 000 " Biochemistry

$316 / 100000$ Porters, assistants, etc.

$41 / 100000$ Total staff

Table 6 Bowel infections

\begin{tabular}{|c|c|c|c|}
\hline Type & Year & Occupation & Comments \\
\hline Salmonella typhimurium & 1980 & MLSO, Microbiology & Beefburger suspected \\
\hline Salmonella $s_{*}^{*}$ & 1981 & $"$ & $\begin{array}{l}\text { Suspected occupational } \\
\text { Same serotype and phage type as recent lab isolate }\end{array}$ \\
\hline Shigella sönei* & $”$ & $”$ & Laboratory accident \\
\hline Shigella boydii* & , & 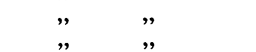 & $\begin{array}{l}\text { Suspected occupational } \\
\text { Laboratory accident }\end{array}$ \\
\hline Shigella flexneri* & $\begin{array}{l}1980 \\
1981\end{array}$ & $"$ & Laboratory accident \\
\hline$" \Rightarrow \quad " \quad *$ & $\begin{array}{c}1981 \\
,\end{array}$ & 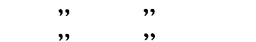 & $\overline{\text { No accident; illness serious }}$ \\
\hline$" \quad " \quad *$ & $”$ & $"$ & Onset after holiday in Italy \\
\hline Campylobacter* & Not known & Medical, Microbiology & $\begin{array}{l}\text { Suspected occupational } \\
\text { Laboratory accident } \\
\text { Virologist; chicken dish suspected }\end{array}$ \\
\hline
\end{tabular}

*"Attributable" attack rate $=165 / 100000$ MLSO Microbiology

$29 / 100000$ Total staff

Table 7 Miscellaneous cases

\begin{tabular}{|c|c|c|c|}
\hline Type & Year & Occupation & Comments \\
\hline Erysipelas* & 1980 & Medical, Morbid anatomy & Occupational \\
\hline Cellulitis (streptococcal)* & $\begin{array}{l}? \\
?\end{array}$ & $"$ & $\eta \quad\}$ same laboratory \\
\hline $\begin{array}{l}\text { Sepsis and absce”ss* } \\
\text { Glandular fever }\end{array}$ & $\begin{array}{c}1981 \\
, "\end{array}$ & $\begin{array}{l}\text { PM techniciän } \\
\text { MLSO, Morbid anatomy }\end{array}$ & Young adult male \\
\hline $\begin{array}{l}\text { Zoster } \\
\quad,\end{array}$ & $"$ & " Haematology "\} & Same laboratory, not connected \\
\hline
\end{tabular}

*Attack rate of occupational sepsis $=251 / 100000$ Medical Morbid anatomy

31/100 000 MLSO, Morbid anatomy

$12 / 100000$ Total staff

infections which show a remarkable concentration in microbiology MLSOs, several of them involved with recognised laboratory accidents. It is also clear from the Table that these workers share the common exposure to food-borne infections at home and abroad of the general population.
Other infections

These are summarised in Table 7 . The only probable occupational infections were the four cases of sepsis all of which affected staff involved with postmortem work, with relatively high attack rate in medical staff. 


\section{Discussion}

This survey is the first product of the extension of the original hepatitis surveys achieved by collaboration between the ACP and the IMLS with encouragement from the Joint Working Party on the Prevention of Infection in Clinical Laboratories. ${ }^{2}$ Extension of the study population by the supplementary IMLS list brought in only an additional eighth, and the small differences in the composition of the supplementary group did not make it unreasonable to combine the data for analysis. Since the effect of this on the calculated attack rates was trivial, comparisons with previous ACP surveys are valid.

The feasibility of surveying infections other than hepatitis had been shown by the pilot study of $1979,{ }^{1}$ though the limited data of this single year (in which it could not be taken for granted that all respondents to the questionnaire had noticed the changed pattern of enquiry) limited confidence in the calculated attack rates. In fact, the attack rates per 100000 for the predominant infections, tuberculosis (42) and bowel infections (33), were remarkably close to those now reported (Table 3 ).

As in previous surveys, none of the cases reported was fatal. All recovered without sequelae, except for one case of tuberculous meningitis which was still under treatment at the time of the enquiry.

Hepatitis, the original target of these enquiries, maintained the low incidence found after 1974 with cases scattered over several occupational subgroups. The few hepatitis B infections which were probably acquired in the laboratory nevertheless involved either working with blood or a laboratory accident. An accident was also reported in the symptomless infection which was excluded from the calculations because of non-comparability with the rest of the data in this and previous surveys which can recognise only illnesses. Information about background immunity, seroconversions and carrier states for hepatitis B would be interesting, but the necessary comprehensive and repeated serological testing has proved unpopular and would probably be impracticable and too costly on a national level. The overall attack rate for hepatitis $B$ calculated from the five cases is 15 . This is similar to that of 14 for the previous five years and compatible with the independently calculated attack rates of 36 for medical laboratory staff and 18 for scientific and technical laboratory staff in England in 1975-79. ${ }^{3}$ The average annual rates based on communicable disease reports of hepatitis $B$ in the general population of England and Wales in 1975-79 were calculated as 4.0 for men and 1.8 for women, these being slight underestimates. ${ }^{3}$

As in 1979, tuberculosis showed numerical pre- dominance. The attack rate of 41 for confirmed cases which seemed probably or possibly to be occupational in origin can be compared with that of 12 for non-occupational cases, with a total attack rate of 53 for the whole survey population. This is considerably higher than the respiratory and nonrespiratory rates of around $14^{4}$ to $18^{5}$ in the general population and confirms previous reports of an increased risk of tuberculosis in clinical laboratory workers $^{6-8}$. Post-mortem and mortuary work was largely associated with the cases, as in one case of 1979.' Reclassification of occupational groups for the three years 1979-81 gives attack rates of 1506 for "technicians" (post-mortem and mortuary) and 2381 for "attendants" (post-mortem and mortuary, including "morticians"). Of the six microbiologists affected, at least two suffered reactivation of endogenous tuberculosis; one infection was attributed to leakage from a defective centrifuge rotor seal when preparing infected specimens-sealed buckets are now used instead. Attention was drawn recently to the special hazards arising from extrapulmonary tuberculosis. ${ }^{9}$

As in 1979, bowel infections affected almost exclusively microbiology MLSOs and all of these infections attributed to laboratory work were in this group. This relationship is clearly significant. Four laboratory accidents were reported in this group including finger contamination during a slide agglutination test and breakage of a wooden swab stick. No typhoid infections were reported, although this has been reported as a hazard of proficiency testing and teaching in the USA. ${ }^{10}$

Of the other infections, the main interest concerns the group of sepsis cases affecting morbid anatomy and post-mortem staff-a reminder that, like tuberculosis, streptococcal infections remain a hazard for these workers. The need for further attention to the risks of infection in this group, notably tuberculosis and sepsis, emerges as one lesson from the survey. The other area of concern is that of microbiology, particularly routine stool examinations and work with enteropathic bacteria, once again indicating the importance of observing strictly the high standards of microbiological technique appropriate to work on the faeces bench. Neither Brucella spp nor $S$ typhi, both significant laboratory hazards, ${ }^{8}$ caused infection in the three years of the present and previous surveys.

This investigation was carried out with the assistance of the ACP, the IMLS, ACP Branch secretaries and of laboratory colleagues who cooperated by returning completed questionnaires for this model, epidemiologically valid survey. The need for similar studies in other countries in order to estimate occupational risks and determine priorities 
for preventive measures is recognised at international level. ${ }^{8}$

I am grateful to Professor Heather Dick and the Joint Working Party for the Prevention of Infection in Clinical Laboratories for their support and encouragement, to Dr RJ Fallon and Dr D Sleigh for helpful criticism of the manuscript, and to my secretary Miss EH Simpson, for help with the conduct of the enquiry and analysis of the data.

\section{References}

' Grist NR. Hepatitis and other infections in clinical laboratory staff. J Clin Pathol 1981;34:655-8.

${ }^{2}$ Grist NR. Hepatitis infections in clinical laboratory staff. Med Lab Sci 1981;38:103-9.

${ }^{3}$ Polakoff S. Tillett HE. Acute viral hepatitis B: Laboratory Reports 1975-9. Br Med J 1982;248:1881-2.

${ }^{4}$ Office of Population Censuses and Surveys. Communicable Disease Statistics 1980, Series MB2 No 7, Table 8 (England and Wales).
${ }^{5}$ Information Services Division, Scottish Home and Health Department, Common Services Agency. Scottish Pulmonary Tuberculosis Survey (SMR 14). 1981.

${ }^{6}$ Reid DD. The incidence of tuberculosis among workers in medical laboratories. $\mathrm{Br}$ Med J 1957;ii:1-4.

${ }^{7}$ Harrington JM, Shannon HS. Incidence of tuberculosis, hepatitis, brucellosis and shigellosis in British medical laboratory workers. Br Med J 1976;i:759-62.

${ }^{8}$ Harrington JM. Health and safety in medical laboratories. Bull WHO 1982;60:9-16.

Allen BW, Darrell JH. Extrapulmonary tuberculosis: a potential source of laboratory-acquired infection. J Clin Pathol 1981;34:404-7.

${ }^{10}$ Blaser MJ, Hickman FW, Farmer III JJ, Brenner DJ, Balows A, Feldman RA. Salmonella typhi: the laboratory as a reservoir of infection J Infect Dis 1980;142:934-8.

Requests for reprints to: Prof NR Grist, University of Glasgow, Department of Infectious Diseases, Ruchill Hospital, Glasgow G20 9NB, Scotland. 